\title{
Programas para la educación rural en el norte de la provincia de Entre Ríos (Argentina, 1978-2018) ${ }^{1}$
}

Programs for rural education in the north of the province of Entre Ríos (Argentina, 1978-2018)

Programas de educação rural no norte da província de Entre Ríos

(Argentina, 1978-2018)

\author{
Eva Mara Petitti \\ Instituto de Estudios Sociales, Consejo Nacional de Investigaciones Científicas y Técnicas, \\ Universidad Nacional de Entre Rios (Argentina) \\ http://orcid.org/0000-0001-8014-7181 \\ marapetitti@gmail.com \\ María Emilia Schmuck \\ Instituto de Estudios Sociales, Consejo Nacional de Investigaciones Científicas y Técnicas, \\ Universidad Nacional de Entre Ríos (Argentina) \\ https://orcid.org/0000-0003-2982-6394 \\ emilia.schmuck@gmail.com
}

\section{Resumen}

El artículo se propone examinar los cambios y las permanencias así como las coexistencias y superposiciones entre los principales programas orientados a la educación rural que se implementaron en la provincia argentina de Entre Ríos y especialmente en el norte, a lo largo de cuatro décadas durante las que se sucedieron diferentes gobiernos, tanto dictatoriales como democráticos (1978-2018). Para ello consultamos normativas nacionales y provinciales, documentos y registros elaborados en el marco de los diferentes programas estudiados, así como también recuperaremos entrevistas y parte del trabajo de campo etnográfico de una investigación previa. A lo largo del trabajo distinguimos cinco programas que en mayor o menor medida, según los casos, han estado superpuestos tanto en lo que respecta a los momentos de inicio y cierre, como a los actores que participaron en los mismos. Mostramos que sus objetivos fundamentales y su organización han sido construidos de manera articulada.

Palabras clave: Políticas Públicas. Educación Rural. Entre Ríos.

\footnotetext{
${ }^{1}$ Este artículo se enmarca en el PID de la UNER "Las políticas públicas en los espacios sociales rurales del norte de Entre Ríos (1978-2018).” Res. 297/2018.
} 


\begin{abstract}
The article aims to examine the changes and permanencies as well as the coexistence and overlaps between the main programs oriented to rural education that were implemented in the Argentine province of Entre Ríos and especially in the north, during four decades during which different governments, both dictatorial and democratic, succeeded each other (1978-2018). For this purpose, we consulted national and provincial regulations, documents and records prepared within the framework of the different programs studied, as well as recovering interviews and part of the previous ethnographic field work. Throughout the work, we distinguished five programs that to a greater or lesser extent, depending on the case, have been overlapping both in terms of the start and end times, as well as the actors who participated in them. We showed that their fundamental objectives and their organization have been built in an articulated way.
\end{abstract}

Key words: Public Policies. Rural Education. Entre Ríos.

\title{
Resumo
}

$\mathrm{O}$ artigo se propõe a examinar as mudanças e permanências, bem como a convivência e sobreposição entre os principais programas de educação rural implementados na província argentina de Entre Ríos e especialmente no norte, ao longo de quatro décadas que diferentes governos seguiram, tanto ditatoriais quanto democráticos (1978-2018). Para isso, consultamos regulamentos, documentos e registros nacionais e provinciais elaborados no âmbito dos diferentes programas estudados, bem como recuperamos entrevistas e parte do trabalho etnográfico anterior. Ao longo do trabalho, distinguimos cinco programas que, em maior ou menor grau, dependendo do caso, foram sobrepostos em relação aos horários de início e término e aos atores que participaram deles. Demonstramos que seus objetivos fundamentais e sua organização foram articulados.

Palavras chave: Políticas Públicas. Educação Rural. Entre Ríos. 


\section{Introducción ${ }^{2}$}

En 1978 el BID aprobó un crédito al gobierno argentino para ejecutar el Programa de Expansión y Mejoramiento de la Educación Rural (EMER), el primer programa diseñado e implementado para la atención de la educación de la población rural en Argentina (Jacinto y Caillods, 2006). Junto al Programa de Expansión y Mejoramiento de la Enseñanza TécnicoAgropecuaria (EMETA) se constituyeron como importantes antecedentes considerados a la hora de realizar los programas posteriores que buscaron extender la escolaridad en contextos rurales (Jacinto y Golzman, 2006). Teniendo en cuenta que cuarenta años después se encuentra en funcionamiento el Proyecto de Mejoramiento de la Educación Rural (PROMER) como principal política pública dirigida a garantizar la educación en los espacios rurales, nos preguntamos cuál fue el devenir de los programas educativos para el desarrollo rural que se ejecutaron a lo largo de 40 años en la provincia de Entre Ríos, desde los estudios de base del EMER hasta la implementación del PROMER.

Contamos con investigaciones generales sobre programas educativos (Jacinto y Caillods, 2006; Jacinto y Golzman, 2006), así como también con estudios que profundizan en determinados programas, como el EMER (Jorge Navarro, 2015, Petitti, 2020a y b), el EMETA (Cragnolino, 2000; Gutiérrez 2012; Leguizamón 2013; Leguizamón y Jorge Navarro, 2013; Plencovich, 2013; Gutiérrez, Jorge Navarro y de Marco, 2014; Frankowski, Romero y Osorio, 2019) y el PROMER (Olmos y Palladino, 2019; Schmuck, 2020; González et al., 2015; Novomisky e Iñiguez, 2015; Brumat, 2011; Yentel, 2011). Para el caso de Entre Ríos, cabe referir además a la investigación de Mayer y Vlasic (2016) que analiza los modelos organizacionales para ampliar la obligatoriedad escolar en los espacios rurales.

En diálogo con esas investigaciones, en el presente trabajo nos proponemos examinar los cambios y las permanencias, así como las coexistencias y superposiciones, entre los principales programas orientados a la educación rural que se implementaron en Entre Ríos y especialmente en el norte de la provincia, a lo largo de más de 40 años, durante los cuales se sucedieron diferentes gobiernos, tanto dictatoriales como democráticos. Se trata de los programas nacionales EMER, EMETA, el Proyecto 7 del Programa Social Educativo (PSE) y el PROMER, los cuales - con la excepción del Proyecto 7- han recibido financiamiento externo. Asimismo, consideraremos el proyecto provincial de Integración de Escuelas Rurales (IER) en base al cual se gestó una propuesta - que finalmente no fue concretada-para extender el EMER y el EMETA a toda la provincia.

Para analizar su articulación, entendemos que aquello que Aguilar (1992) sostiene para las etapas de las políticas públicas es posible de aplicar al estudio de los programas para la educación rural, entendiendo que los mismos "pueden sobreponerse y superponerse" unos a otros, "condensarse" alrededor de uno de ellos, "anticiparse o atrasarse, repetirse". Así como es artificial "separar en diversos tramos la elaboración de una política" (Aguilar, 1992: 15), estudiar los programas orientados a la educación rural por separado conlleva el riesgo de perder buena parte de la complejidad que implica el vínculo que se establece entre los mismos.

En un trabajo anterior hemos visto que los diferentes actores involucrados en el EMER presentan importantes diferencias al señalar el momento de inicio y de finalización y que ello pudo estar vinculado a que tuvo diferentes dependencias institucionales; a que adquirió ritmos desparejos no solo en cada departamento sino también en cada conjunto nuclearizado y a la dificultad de asociar su inicio con el periodo de la dictadura militar (Petitti, 2020a). Ahora bien, también es posible que las diferentes precisiones respecto al inicio y al cierre se relacionen con las superposiciones entre los diferentes programas.

\footnotetext{
${ }^{2}$ Para alivianar la redacción, a lo largo del trabajo se utilizará el masculino genérico clásico, en el entendido que incluye siempre a mujeres y hombres.
} 
El EMER tuvo como espacio de ejecución cuatro departamentos ubicados al norte de Entre Ríos -Feliciano, La Paz, Federal y Federación-, los cuales a partir de entonces se constituyeron como zona de atracción de otros programas de desarrollo rural. ${ }^{3}$ El norte ha sido excluido por diferentes analistas a lo largo del siglo XX como un área marginal del modelo económico agroexportador (Brasky y Pucciarelli, 1997). Predominan los suelos con limitaciones para la actividad agrícola, que restringen la elección de cultivos y/o requieren un manejo muy cuidadoso (Engler, 2008) y presentan una significativa disminución de rutas y caminos de asfalto en relación al resto de la provincia. En lo que respecta a la población, de los 17 departamentos que configuran la actual división político-administrativa de la provincia, se encuentran entre los que menos han crecido en el período censal 2001/2010 y entre los que tienen mayor porcentaje de población rural. ${ }^{4}$ Asimismo, poseen un alto índice de Necesidades Básicas Insatisfechas ${ }^{5}$ y en lo que respecta a los índices de analfabetismo, en algunos casos llegaban a duplicar el promedio provincial: La Paz presentaba un 4.1\%, Feliciano un $4.2 \%$ y Federal un $4.8 \%$. Federación, por su parte, presentaba un $2.6 \%$.

Para la realización de este artículo consultamos normativas nacionales y provinciales, documentos y registros elaborados en el marco de los diferentes programas estudiados, hallados en el Archivo Histórico de Entre Ríos, el Archivo del Consejo General de Educación de Entre Ríos (CGE), el Centro de Documentación del CGE, y el Centro de Documentación de la Biblioteca Nacional del Maestro. Además, recuperaremos entrevistas a diferentes actores involucrados y parte del trabajo de campo etnográfico que hemos realizado desde 2017 en escuelas primarias y secundarias rurales de los departamentos La Paz y Feliciano. Si bien nos enfocaremos en el norte entrerriano para estudiar la dinámica particular en el territorio, no perderemos de vista la totalidad de la provincia.

\section{El Programa de Expansión y Mejoramiento de la Educación Rural}

Desde la implementación de la Alianza para el Progreso, los espacios rurales de América Latina han sido destinatarios de programas para el desarrollo rural a la vez que el proyecto desarrollista postulaba que era "indispensable que los miembros de la sociedad alcanzaran un determinado nivel educativo para asegurar su desarrollo económico" (Cragnolino 2000: 180). A partir de entonces cobraron importancia los préstamos de organismos de financiamiento externo y, como advierte Estrada Álvarez, el BID en conjugación con el ideal de desarrollo económico moderno "fue concebido como un mecanismo de contención de las presiones comunistas, socialistas y progresistas que en la segunda posguerra caracterizaban a América Latina" (2009: 12). En 1976, bajo sus auspicios se llevó a cabo en Washington el primer "Seminario sobre Alternativas financieras de programas y proyectos orientados a las nuevas prioridades educativas de América Latina". 6

Dos años después, durante el gobierno de la dictadura militar (1976-1983) y coincidiendo con la transferencia de los establecimientos de nivel primario y pre primario

\footnotetext{
${ }^{3}$ En este sentido podemos mencionar el Programa de Desarrollo del centro-norte y Plan de Reactivación Económica del Norte Entrerriano en 1983, el Programa Bases para el Desarrollo Sustentable del Norte Entrerriano en 1994 y el Proyecto de Desarrollo centro-norte a cargo de la Subsecretaría de Asuntos Agrarios, del INTA y del Instituto Interamericano de Cooperación para la Agricultura en 1995. Asimismo, un informe realizado por el gobierno provincial en 2016 sobre la zona destaca que es la región que "presenta menor desarrollo en la provincia" con el fin de que sea contemplada para recibir inversiones.

${ }^{4}$ Hacia 2010, mientras la población rural de la provincia representaba un 14.3\%, en el departamento Federación ascendía a un $18 \%$, en La Paz a un $21 \%$, en Federal a un $27 \%$ y en Feliciano al $32 \%$.

${ }^{5}$ Según el Censo Nacional de 2010 contaban con los mayores índices de la provincia $(8,4 \%)$, exceptuando a Islas del Ibicuy (19\%): Federación encarnaba un $10 \%$, La Paz y Federal un 12\% y Feliciano un 16\% (INDEC, 2010).

${ }^{6}$ Banco Interamericano de Desarrollo Alternativas financieras para las prioridades educativas de América Latina San José de Costa Rica, 1980.
} 
a las provincias, ${ }^{7}$ el BID le otorgó al gobierno nacional un crédito de 50 millones de dólares con una contraparte similar de la nación, que dio lugar al Programa de Expansión y Mejoramiento de la Educación Rural, conocido por sus siglas como EMER. En un primer momento se enunciaba como su objetivo "la eliminación de escuelas rancho". ${ }^{8}$ A lo largo de su implementación se fueron incorporando nuevos propósitos que excedían la cuestión edilicia orientándose a brindar un servicio escolar acorde con las características regionales, aumentar los índices de retención vigentes, reducir los casos de alumnos repitentes, de desgranamiento y de deserción. Asimismo, se buscó proporcionar una orientación laboral a los alumnos de grados superiores y eventualmente también a los adultos miembros de esa comunidad a fin de propiciar adecuadamente el arraigo poblacional en la zona, mejorar la calidad de vida de los habitantes y de las comunidades de su esfera y acción. ${ }^{9}$

Entre 1979 y 1983, se firmaron los convenios con todas las provincias de país con la excepción de Buenos Aires y el Territorio Nacional de Tierra del Fuego, Antártida e Islas del Atlántico Sur. ${ }^{10}$ La coordinación y administración a nivel nacional quedó a cargo de una Unidad Ejecutora Central (UEC) bajo dependencia del Ministerio de Cultura y Educación, que fue responsable de la evaluación del estudio que permitió avalar la solicitud de crédito, actuó como ente coordinador para la ejecución y administración de los recursos del programa y estableció vínculos con las Unidades Ejecutoras Provinciales (UEP) encargadas de la administración y ejecución en el plano local. Las UEP eran entes descentralizados con jerarquía de subsecretaría de estado y estaban integradas por un coordinador, elegido por el Poder Ejecutivo, un asesor legal, un secretario y cuatro áreas: Educación, Infraestructura y equipamiento, Administrativo-Contable, Seguimiento y Evaluación.

Para recibir el dinero, que no era reintegrable para las provincias, las mismas debían realizar estudios de perfectibilidad y factibilidad y decidir qué departamentos y escuelas se incluirían. La propuesta debía ser evaluada por la UEC y el BID. Ahora bien, los recursos para realizar los estudios y la propuesta debían ser aportados por las provincias. En el caso de Entre Ríos se tomaron los vehículos y el personal del Consejo Provincial de la Región de Salto Grande del Gobierno de Entre Ríos (COPRESAG). El COPRESAG fue creado en abril de 1976 para hacerse cargo de la construcción y ejecución del realojamiento de la población de Federación con motivo de la inundación de la que fue objeto para crear la represa de Salto Grande (Catullo, 2006: 214). Los vínculos del BID y el COPRESAG tenían su origen en 1972, cuando en "lo que entonces fue el mayor préstamo de la historia del BID” le otorgó a Argentina y Uruguay 80 millones de dólares para construir la central hidroeléctrica de Salto Grande (Bouzas y Knaack, 2009).

De acuerdo a los criterios de elegibilidad establecidos por el BID, la determinación de los departamentos o partidos a considerar dentro de cada provincia estuvo sujeta a la magnitud de la población rural en edad escolar, la accesibilidad de las zonas "a las mayores concentraciones de población rural en sus respectivas áreas de influencia" y la procedencia de "los niveles socioeconómicos más bajos de la provincia." Por otra parte, era necesario que evidenciara que el proyecto era compatible con otros proyectos de

\footnotetext{
${ }^{7}$ Nos referimos a la promulgación de las leyes 21.809 y 21.810 de transferencia de servicios educativos que traspasaron alrededor de 6.500 escuelas pre primarias y primarias, supervisiones y juntas de clasificación que hasta entonces dependían del Consejo Nacional de Educación, a la Municipalidad de la Ciudad de Buenos Aires, el Territorio Nacional de la Tierra del Fuego, Antártida e Islas del Atlántico Sur y las provincias.

8 “Tres préstamos BID a nuestro país" El Diario, 17/4/78, p. 1 y El Diario, 12/7/78, p. 3.

9 Provincia de Entre Ríos. Unidad Ejecutora Provincial. Programa EMER. Puesta en marcha de la modalidad nuclearizada, 1987.

${ }^{10}$ Consejo Federal de Cultura y Educación. Secretaría Permanente. Capítulo 1. Resoluciones y recomendaciones aprobadas. Buenos Aires, octubre de 1983 Memoria del Consejo Federal de Educación 1976-1983.
} 
desarrollo económico-social. ${ }^{11}$ Como hemos mencionado, se seleccionó a aquellos ubicados al norte - Feliciano, Federal, La Paz y Federación- los cuales, sobre todo los tres primeros, poseían altos índices de ruralidad, analfabetismo y deserción escolar y, en el caso de Federación, había estado vinculado al COPRESAG. De las 210 escuelas rurales existentes en los cuatro departamentos, se seleccionaron un poco más de la mitad para ser incluidas. Sin embargo, se habían presentado otras propuestas -la zona sur que corresponde al departamento Islas del Ibicuy, cuyos índices de ruralidad y analfabetismo son los mayores de la provincia, y el departamento de Villaguay-que más adelante, como veremos, fueron incorporadas a otros proyectos de nuclearización.

En 1981, una vez aprobado el proyecto presentado por la provincia, Entre Ríos comenzó a recibir los recursos para poner en marcha el programa que ascendían a 6.3 millones de dólares. Los mismos se estructuraban en dos grandes componentes. El que recibía la mayor distribución era el sector de infraestructura y equipamiento (89\%), que estaba destinado a la construcción y refacción de edificios escolares, la compra de los vehículos para realizar la nuclearización y la adquisición de insumos y equipamiento. El otro componente $(11 \%)$ era destinado a la formación docente y reelaboración curricular.

La articulación del EMER con el COPRESAG continuó al menos hasta diciembre de 1983. Durante ese periodo, la UEP del EMER y el COPRESAG emitieron diversas resoluciones afectando a su personal a cumplir tareas en ambas reparticiones. ${ }^{12}$ Pero además, con la excepción del área de educación, las tres áreas restantes de la UEP -Infraestructura y equipamiento, Administrativo-Contable y Seguimiento y Evaluación- estuvieron integradas en gran medida por personal del COPRESAG. ${ }^{13}$ Es decir, que si bien se trataba del primer programa diseñado e implementado para la atención de la población rural en Argentina, se constituyó sobre la base existente de un Consejo creado en el marco del Programa de Relocalización de Federación para la creación de la represa de Salto Grande que recibió financiamiento del BID.

Las primeras actividades que se realizaron entre 1981 y 1984 estuvieron vinculadas a investigación, perfeccionamiento docente y reforma de curricular. El retorno a la democracia, que en la provincia de Entre Ríos estuvo representado por el dirigente de la UCR Sergio Montiel (1983-1987), implicó cambios en la dirección de la UEP del EMER. Sin embargo, buena parte del personal que se desempeñaba en el área educativa continuó trabajando, lo que ocasionó ciertos roses con aquellas personas que ingresaron al CGE posteriormente al retorno democrático (Petitti, 2020b).

Entre 1984 y 1987 se llevaron las acciones de edificación escolar y equipamiento que se habían iniciado durante el periodo anterior y en 1987 se comenzó a implementar la nuclearización. La misma consistía en la organización de conjuntos nuclearizados, integrado cada uno por una escuela núcleo -dotada y equipada para ofrecer servicios educativos a sus alumnos y a los de otras escuelas- y un determinado número de escuelas satélites en cierto radio de distancia que asistían una o dos veces a la semana a la escuela núcleo para realizar talleres de orientación laboral, trasladados en una camioneta comprada para tal fin. ${ }^{14}$ El EMER en Entre Ríos estaba integrado por 20 conjuntos nuclearizados que abarcaban 114 escuelas.

${ }^{11}$ Consejo Federal de Cultura y Educación. Secretaría Permanente. Capítulo 1. Resoluciones y recomendaciones aprobadas. Buenos Aires, octubre de 1983 Memoria del Consejo Federal de Educación 1976-1983.

12 Véase "Firmase un Convenio sobre extensión y mejoramiento de la educación rural." El Diario, 12/8/80 p. 6 y Gobierno de Entre Ríos. UEP Programa EMER. Resoluciones EMER 1983. De los 33 contratos celebrados para la presentación de servicios con fondos provinciales aprobados el 30 de diciembre de 1983, 21 prestaban servicios simultáneamente al COPRESAG.

${ }^{13}$ Gobierno de Entre Ríos. UEP Programa EMER. Resoluciones EMER 1983.

${ }^{14}$ Los talleres del área de orientación laboral consistían en cursos electricidad, soldadura o carpintería para los varones y artes del hogar - corte y confección y cocina - para las mujeres, área agropecuaria - huerta, jardín, pequeño vivero y cría de pequeños animales - y un área artístico expresiva - música y educación física. 


\section{El Programa de Expansión y Mejoramiento de la Enseñanza Técnico Agropecuaria}

Simultáneamente al desarrollo del Programa EMER, en junio de 1983 se aprobó un nuevo préstamo del BID, esta vez de 78.5 millones de dólares, que con una contraparte de la nación de 54.9 millones se utilizó para financiar el EMETA. Si bien algunas de sus primeras etapas, como la realización de convenios, se efectuaron durante la dictadura militar, su implementación inició a partir del gobierno democrático.

El EMETA tenía como objetivo promover una propuesta de cambio para la educación formal y no formal orientada al sector agropecuario. Esta propuesta, que en un comienzo estuvo pensada para 30 establecimientos, se desarrolló en 47 escuelas y 244 centros no formales que se ubicaron en 22 provincias y 3 universidades. ${ }^{15}$ La Educación No Formal consistió en acciones desarrolladas a partir de la relación entre la escuela agrotécnica y las escuelas rurales primarias, por un lado, y por otro en el desarrollo de acciones de capacitación puntal y micro emprendimientos fuera y dentro de la escuela.

En Entre Ríos, a fines de 1984 aún no se habían podido llevar a cabo desde el CGE los estudios con destino a obtener una caracterización de las zonas de la provincia donde se ubicarían las escuelas y presentar el proyecto a la UEC del EMETA. Con el fin de poder obtener el financiamiento para la provincia, la gestión del CGE decretó declarar de interés la creación del EMETA en Entre Ríos y para el cumplimiento de las pautas requerir el apoyo administrativo a la coordinación de la UEP EMER. ${ }^{16}$ En julio 1986, cuando había finalizado el financiamiento destinado al EMER en la provincia y era necesario incorporar remanentes de fondos nacionales y partidas de las rentas generales del presupuesto provincial para cumplir las acciones pendientes de ejecución, se decretó crear la UEP EMER-EMETA y el EMER se incorporó al EMETA. ${ }^{17}$

En marzo de 1987 el EMER pasó a depender del CGE. El decreto disponía que el CGE a través de la dirección de enseñanza y las direcciones departamentales de los departamentos incluidos, insertaran gradualmente las acciones del EMER dentro de sus estructuras de funcionamiento para ir expandiendo esta modalidad a otras escuelas rurales. ${ }^{18}$ Ese mismo año el proyecto EMETA fue aprobado por la UEC y Entre Ríos recibió 5.5 millones de dólares no reintegrables para su ejecución. Al igual que en el EMER, se estructuraron en dos grandes componentes, un $94 \%$ estaba destinado a infraestructura y equipamiento y el restante $6 \%$ a desarrollo institucional. Uno de los responsables del programa a nivel nacional señala que:

El Programa EMETA fue una lucha en el sentido de que siempre fue pensado como un programa de equipamiento e infraestructura y lo pedagógico era algo marginal. Nosotros quisimos darle justamente centralidad a lo pedagógico y fue una lucha, fue una lucha porque había que pelearse con las grandes inversiones. Lo grande del programa $(. .$.$) eran fondos para construcciones y equipamiento, el$ resto con mucha suerte para capacitación, por decir así. (...) En algunos lados se construían unos edificios, porque era un acuerdo más político entre el gobierno provincial y el gobierno nacional. Entonces decidían hacer una construcción majestuosa en Humahuaca y no se fijaban si había chicos para que vayan a la escuela. (Entrevista a responsable nacional del EMETA, 25/6/20).

\footnotetext{
${ }^{15}$ Consejo Federal de Cultura y Educación. Secretaría Permanente. Memorias años 1976-1983, Buenos Aires, octubre 1983.

${ }^{16}$ Poder Ejecutivo, Entre Ríos, Decreto 4424/84

${ }^{17}$ Poder Ejecutivo, Entre Ríos, Decreto 3158/86 y Poder Ejecutivo, Entre Ríos Decreto 485/87.

${ }^{18}$ Poder Ejecutivo, Entre Ríos, Decreto 1399/87.
} 
En noviembre, coincidiendo con la asunción del primer mandato del gobernador del partido justicialista Jorge Busti (1987-1991), se aprobó y puso en vigencia el reglamento de la UEP del Programa EMETA. ${ }^{19}$ Así, el EMETA era ejecutado y administrado en la provincia de Entre Ríos por la UEP, organismo descentralizado, dependiente del Ministerio de Gobierno, Justicia y Educación, el cual mediante convenios accionaba conjuntamente con el CGE y la subsecretaría de Asuntos Agrarios. En 1988 se realizaron los estudios de base en las cuatro localizaciones destinatarias del programa, con la directa participación de los involucrados en la práctica educativa. A fines de 1988 el Poder Ejecutivo provincial organizó la Comisión Integradora para la Educación Agropecuaria (CIPEA), integrada por el Secretario Ministerial de Asuntos Agrarios, el Presidente del CGE y el coordinador ejecutivo de los programas EMER-EMETA. Dependían de la CIPEA la UEP EMETA y la Unidad de Seguimiento y Evaluación del EMER que se creó en 1988.

El EMETA amplió geográficamente su accionar en relación al EMER. A los departamentos La Paz, Feliciano, Federal y Federación, se incorporaron Villaguay y Concordia, extendiéndose así al centro norte de la provincia. Las escuelas agrotécnicas de base eran cuatro y estaban localizadas en los departamentos Villaguay, Concordia, La Paz y Federación. Cada una de ellas tenía dos escuelas agrotécnicas vinculadas y cuatro escuelas primarias rurales. Con la inclusión de los Centros No Formales, se sumaron al EMETA los departamentos Colón y Rosario del Tala, así como Paraná.

Se basó en el trípode educación-trabajo-producción. Dentro del espíritu del programa estaba el de trabajar coordinadamente con todas aquellas instituciones públicas y privadas que de una u otra manera estaban relacionadas con los objetivos del mismo y con la comunidad rural en general. En Entre Ríos el objetivo del EMETA era la renovación del subsistema de educación agropecuaria en la provincia y para ello pretendía contribuir a la formación de un mayor número de técnicos agropecuarios y auxiliares técnicos de nivel medio que respondan a los requerimientos del medio rural; diversificar la oferta educativa para el sector agropecuario, ajustándolas a las necesidades de desarrollo de la provincia; ampliar los alcances de la educación técnica agropecuaria, incorporando a los grupos menos favorecidos en el orden socioeconómico, promover la educación no formal y prestar servicios técnicos al sector agropecuario del área de influencia de la unidad escolar. ${ }^{20}$ En el transcurso del desarrollo de las acciones se fueron ampliando sus objetivos. Así, las escuelas agrotécnicas de base, además de brindar cursos de capacitación, se consolidaron como espacio de discusión para que los pobladores de la comunidad desarrollaran proyectos de acción social.

\section{El Proyecto de Integración de Escuelas Rurales (IER) y la propuesta de extender la nuclearización a toda la provincia}

En 1988, en el marco del Proyecto Central de Descentralización y Regionalización se creó el Proyecto de IER. Según los documentos oficiales, la integración de escuelas rurales surgió "como la posibilidad de comenzar un proceso de descentralización y regionalización del sistema educativo provincial, a través de la micro planificación, la democratización de las relaciones educativas y la participación de la comunidad". ${ }^{21}$

\footnotetext{
${ }^{19}$ Poder Ejecutivo, Entre Ríos, Decreto 5488/87 que crea la Unidad Ejecutora Provincial del Programa EMETA y Decreto $7489 / 87$ que deroga al anterior.

${ }^{20}$ Provincia de Entre Ríos. Proyecto de Expansión y Mejoramiento de la Educación Técnico Agropecuaria, s/f; Provincia de Entre Ríos. UEP. EMETA. Propuesta de Diseño Curricular para el Subsistema de Educación Agrotécnica, s/f.

${ }^{21}$ Entre Ríos. CGE. Regionalización y Descentralización. IER. Talleres Gráficos del Banco de Entre Ríos, Paraná, 1991; Entre Ríos. CGE. Regionalización y Descentralización. Manual de Competencias, Talleres Gráficos del Banco de Entre Ríos, Paraná, 1990.
} 
Según argumentaban quienes estuvieron involucrados en el proyecto, la experiencia se fundamentó en las demandas de las comunidades educativas y la labor promotora de las coordinadoras para superar el aislamiento de los alumnos y el insuficiente desarrollo del área estético-expresiva en escuelas de personal único o reducido que no contaban con cargos de maestros para el área. A ello se sumaba la posibilidad de aprovechar las experiencias, habilidades y conocimientos de miembros de la comunidad y la necesidad de participación organizada de los padres, alumnos, docentes y la comunidad de la zona (Entrevistas a referentes del Proyecto IER, 30/10/19; 4/11/19; 15/11/19 y 29/01/20). Ahora bien, por otra parte, desde los documentos elaborados en el marco del programa se planteó además como una iniciativa que partió desde el CGE. ${ }^{22}$

El objetivo de la integración de escuelas rurales era convocar a la comunidad para reflexionar sobre las necesidades educativas básicas de la zona, establecer prioridades, aunar criterios de acción para abordar los nudos problemáticos y diseñar proyectos autogestionarios, rescatar y articular recursos humanos y materiales propios y del sistema central y generar, desde una nueva concepción de aprendizaje, contextos que permitan la valoración y la recreación del saber cultural de la zona. Ha sido planteado como "el camino propicio para el arraigo y el otorgamiento de un rol protagónico y comunitario a la población rural". ${ }^{23}$

El Proyecto IER se comenzó a implementar en 1989 en los departamentos Paraná y Tala y al año siguiente se avanzó en los departamentos Nogoyá, Islas y Diamante. Las escuelas agrupadas se reunían mensualmente con la excepción de Tala, donde lo hacían cada quince días. Los encuentros se realizaban en un lugar fijo (escuelas con mayores comodidades o equidistantes del grupo) o en forma rotativa en cada una de las escuelas núcleo. La duración de cada encuentro oscilaba entre seis y cuatro horas (sin contar el tiempo de traslado), a veces durante la mañana y la tarde. Tanto el cronograma como el lugar y la duración de los encuentros se consensuaban con cada núcleo.

La nuclearización en el Proyecto IER era entendida como una forma organizativa de las escuelas que se basa en la agrupación, a través de una red institucional de las unidades escolares de un área determinada, para el logro de objetivos de mejoramiento cualitativo de la enseñanza. Así, posibilitaba que durante el encuentro los alumnos recibieran clases y talleres del área de expresión y creatividad, artesanales, primeros auxilios, conocimientos agropecuarios, carpintería y electricidad. Tal como se puede observar, varios de los talleres eran sobre áreas similares a los que se desarrollaban en el EMER. De la misma manera, tenían lugar actividades de perfeccionamiento para los docentes y de promoción de la comunidad para los padres en actividades en las que participaban delegados de las diversas instituciones municipales como la Junta de Gobierno, la Comisaría y los Centros de Salud.

Si bien se basaba en la nuclearización y las temáticas de los talleres tenían similitudes con las del EMER, los documentos del IER subrayan una serie de elementos que lo diferenciaban. Así, se resalta el hecho de que no tenían financiamiento externo, que las iniciativas surgían de las comunidades y que se desarrollaba en el marco de la descentralización. Había otra diferencia, no mencionada como tal, y es el hecho de que la periodicidad era menor.

Como el IER contaba con escasos recursos que provenían del CGE, el traslado (de coordinadores, monitores, docentes, artesanos, niños y padres), que era el eje central de la nuclearización, en más de una oportunidad se resolvía con vehículos propios. También se utilizaban vehículos de algunas municipalidades, de las direcciones departamentales, de las escuelas agrotécnicas y de los maestros rurales de las instituciones incluidas. Los municipios o el CGE, a través de fondos otorgados por el Instituto de Seguro de la provincia de Entre Ríos,

\footnotetext{
${ }^{22}$ Entre Ríos. CGE. Regionalización y Descentralización. IER. Talleres Gráficos del Banco de Entre Ríos, Paraná, 1991.

${ }^{23}$ Entre Ríos. CGE. Regionalización y Descentralización. IER. Talleres Gráficos del Banco de Entre Ríos, Paraná, 1991.
} 
reintegraban el gasto de combustible. Una de las responsables recuerda que "a mi marido le destruí dos autos. El CGE pagaba el combustible, pero el que tenía auto ponía su auto". (Entrevista a responsable del Programa IER, 4/11/19).

En 1991, poco antes de que finalizara la gestión de Busti y que los programas EMER-EMETA e IER dejaran de funcionar en la órbita del CGE, las responsables de éstos elaboraron una iniciativa conjunta para extender la nuclearización a toda la provincia colocando a ambos como antecedentes. La iniciativa se titulaba "Pre proyecto Programa de Integración de servicios educativos rurales." El objetivo era superar el aislamiento de los docentes y los pobladores rurales, generando y manteniendo procesos de comunicación que significaran la inclusión de la escuela en el medio local, regional, nacional y mundial. Ello se enmarcaba en una invitación elaborada desde el ámbito nacional para la elaboración de nuevos proyectos, en la cual Entre Ríos acordó escoger como línea de trabajo la mejora de la calidad de la oferta educativa para áreas rurales. ${ }^{24}$

La propuesta consistía en conformar un único programa desde la experiencia del Proyecto IER y EMER-EMETA con el objetivo de apropiarse para la educación rural de los elementos más sustanciosos y "consolidar institucionalmente un espacio de respuestas políticas, educativas y administrativas propias para el medio rural." A pesar de que el Proyecto IER procuraba diferenciarse del EMER, los ejes del "Pre proyecto Programa de Integración de servicios educativos rurales" fueron profundizar y expandir. Por un lado, profundizar la nuclearización como estrategia de organización y producción de servicios y fortalecer las líneas de trabajo de la Educación No formal. Por otro lado, expandirla en aquellas escuelas primarias rurales donde se hubieran iniciado acciones autogestionarias similares a la modalidad nuclearizada y en el resto de las escuelas agrotécnicas de la provincia. ${ }^{25}$

El Pre Proyecto procuró conformar e instalar una oferta educativa que cubriera las necesidades de los pequeños y medianos productores por ser ejes en el desarrollo zonal y estar social y económicamente postergados de las organizaciones existentes y de las decisiones inherentes al desarrollo del sector, poniéndose un énfasis especial en la incorporación de la mujer y la familia rural con unidades productivas en marcha y localizadas en la zona de influencia de las escuelas primarias y agrotécnicas existentes. También se encontraban dentro de sus destinatarios los técnicos medios, trabajadores rurales en relación de dependencia, maestros, profesores y directores de escuelas rurales.

Coincidiendo con la asunción del gobernador entrerriano del partido justicialista Mario Moine (1991-1995) -durante la cual se creó la Secretaría de Educación encargada de los institutos de nivel superior y las escuelas medias transferidas en $1992-{ }^{26}$ tanto el EMER y el EMETA como el Proyecto IER dejaron de tener un espacio en el CGE y las responsables fueron enviadas a otras áreas. Esto no impidió que en algunas escuelas se continuaran llevando a cabo actividades de nuclearización. Mientras que en un conjunto nuclearizado encontramos registros de que el traslado de alumnos se extendió hasta junio de 1992, hay casos localizados en Federal y La Paz donde los traslados se siguieron realizando. Así, en uno de ellos las actividades de cierre anual del Programa EMER continuaron hasta al menos 1994 y en otro los traslados se realizaron hasta julio $1998 .{ }^{27}$ Por otra parte, a comienzos de los '90 en algunos establecimientos se comenzó a nuclearizar el nivel inicial, lo que posibilitó que los traslados se extendieran durante un tiempo mayor. Una de las técnicas advertía que no era posible fijar un momento exacto respecto a la

\footnotetext{
${ }^{24}$ CGE. Pre proyecto "Programa de integración de servicios educativos rurales." Elaborado por UEP Programas EMER EMETA, Provincia de Entre Ríos, septiembre de 1992.

${ }^{25}$ CGE. Pre proyecto "Programa de integración de servicios educativos rurales." Elaborado por UEP Programas EMER EMETA, Provincia de Entre Ríos, septiembre de 1992.

${ }^{26}$ El traspaso de los institutos de nivel superior y las escuelas medias conllevó la creación en 1991 de una Secretaría de Educación encargada de dichos niveles, la cual fue suprimida en 1995.

27 Archivo Escuela 48, Federal, Archivo Escuela 11, La Paz y Archivo escuela 69, La Paz. Incluso en la provincia de Misiones, en algunos conjuntos nuclearizado las actividades se realizaron hasta el año 2016.
} 
finalización del Programa EMER en Entre Ríos: "Es un proceso, no es que un día cierra como un negocio". (Entrevista a responsable del área educativa del EMER, 23/5/18).

\section{El Proyecto 7: el tercer ciclo EGB en las escuelas del campo}

Durante la presidencia de Carlos Menem (1989-1999), la reforma educativa fue respaldada por préstamos del Banco Mundial (BM) y del BID y se desplegó con especificidades en todo el país. La Ley Federal de Educación de 1993 prolongó la escolaridad obligatoria de 7 a 10 años, denominándola Educación General Básica (EGB) y dividiéndola en tres ciclos de tres años. Además, en 1992 con la Ley de Transferencia se culminó el proceso de descentralización nacional, realizándose el traspaso de los servicios educativos no universitarios y las escuelas medias a las provincias.

Con el fin de facilitar la implementación del tercer ciclo de EGB en las zonas rurales y ampliar la oferta educativa considerando las particularidades del medio se desarrolló el Proyecto 7 de Fortalecimiento de la Educación Rural-EGB 3. Este programa fue parte del Plan Social Educativo (PSE), que estuvo vigente entre 1993 y 1999 y englobó una serie de políticas llamadas "compensatorias" estipuladas por la Ley Federal de Educación. ${ }^{28}$

El PSE abarcó a todas las provincias, alcanzando mayor cobertura en las zonas definidas como de "mayores necesidades". La focalización fue así entendida en un sentido amplio, buscando alcanzar un gran número de escuelas y un alto porcentaje de la matrícula escolar. La mayor parte del financiamiento estuvo destinada a la edificación escolar y la provisión de libros, obras y equipamiento didáctico para los alumnos y las escuelas, perfeccionamiento docente, apoyo a proyectos locales e institucionales, entre otras iniciativas. En lo que respecta a los espacios rurales, al igual que en el EMER, la "erradicación" de las llamadas "escuelas-ranchos" fue uno de los logros más difundidos. Así, el compromiso con la "población escolar más carenciada"29 y la concepción de la educación rural no mostraban grandes diferencias con el programa financiado por el BID.

El Proyecto 7 inició en 1996 y hacia 1999 abarcaba alrededor del 24\% del total de escuelas rurales en 21 provincias (Prudant y Scarfó, 2018). El gobierno central aportaba los gastos de inversión y cada provincia adecuaba la propuesta a sus estrategias, prioridades y recursos disponibles, haciéndose cargo de los gastos corrientes como la designación de los cargos docentes y el transporte del equipo de profesores itinerantes (Jacinto y Golzman, 2006; Prudant y Scarfó, 2018).

En el marco del Proyecto 7, en la provincia de Entre Ríos se eligieron seis departamentos para realizar una prueba piloto entre 1997 y 1998 que diera inicio al proceso de creación del tercer ciclo de la EGB. Federal y La Paz habían participado del EMER y a mediados de los '90 contaban con conjuntos nuclearizados que continuaban realizando los traslados. Nogoyá y Paraná habían participado de la experiencia de integración de escuelas rurales. A ellos se sumaban Concordia en la costa del Río Uruguay y Victoria, en la del Paraná. En 1997 se crearon cursos para garantizar el nuevo ciclo en 16 escuelas y al año siguiente se incorporaron 56 más. ${ }^{30}$ Así, en 1998, la implementación del EGB 3 en la zona

\footnotetext{
${ }^{28}$ En un primer momento, el PSE estuvo estructurado en base a dos grandes programas, Mejor educación para todos y Mejoramiento de la Infraestructura escolar. Desde 1997 incorporó el Programa Nacional de Becas, que a diferencia de los dos anteriores que contaban con financiamiento del presupuesto nacional, se desarrolló a través de un crédito del BID. El PSE estableció que el Poder Ejecutivo debía financiar programas especiales de desarrollo educativo que encaren las diversas jurisdicciones con la finalidad de "solucionar emergencias educativas, compensar desequilibrios educativos regionales, enfrentar situaciones de marginalidad, o poner en práctica experiencias educativas de interés nacional". Argentina. Ley Federal de Educación No 24.195, 1993, artículo Nº 64.

29 Argentina. Ministerio de Cultura y Educación. Plan Social Educativo: Programa mejor educación para todos. 1994, página 5.

${ }^{30}$ Provincia de Entre Ríos, CGE Resolución 1445/97 y CGE Resolución 0080/98.
} 
rural de la provincia abarcó 72 escuelas, 340 alumnos de $7^{\circ}$ año y 113 de $8^{\circ}{ }^{31}$ Según el criterio estipulado para la elección de las instituciones, que quedaba a cargo de cada provincia, se debían privilegiar las zonas que presentaban menores índices de Necesidades Básicas Insatisfechas (Prudant y Scarfó, 2018). En Entre Ríos, se destaca que las instituciones fueron seleccionadas por las autoridades, sin consulta a las escuelas, lo que al tiempo que implicó una atención sobre ciertas instituciones y maestros rurales que significaba una novedad y contrastaba con la recibida por otras escuelas en el medio rural, se tradujo en un cúmulo de trabajo extraordinario insuficientemente recompensado (Celman et al., 2000).

Para la implementación del Proyecto 7 se valoraron los antecedentes de la articulación entre instituciones rurales que se había experimentado en el EMER y el EMETA, aunque en lugar de privilegiar el traslado de los estudiantes se buscó conformar equipos integrados por un "maestro tutor" en cada institución -que debía garantizar el seguimiento de la trayectoria escolar de los estudiantes- y profesores itinerantes -que dictaban las áreas curriculares específicas en diferentes escuelas. Así, se crearon Unidades de Gestión Local (UGL) agrupando escuelas que se encontraban ubicadas en zonas geográficas cercanas para que trabajaran articuladas en torno a una sede que funcionaba como su referencia física y administrativa. Como referentes de cada UGL se designaba a la persona encargada de la supervisión del nivel primario y la directora o director de la escuela primaria, que ahora también quedaba a cargo del nuevo ciclo (Jacinto y Golzman, 2006). Entre las opciones que albergó la provincia de Entre Ríos, además, se encontró la posibilidad de disponer el funcionamiento del tercer ciclo con secciones móviles, en las que los alumnos se trasladaban una vez a la semana para tener clases de tecnología e inglés en una escuela media, a la que pertenecían los profesores que dictaban estas asignaturas y desde donde se articulaban acciones para la formación y asesoramiento de los maestros de la escuela EGB a cargo del tercer ciclo. ${ }^{32}$

El acompañamiento a la implementación del EGB 3 por parte del Proyecto 7 estuvo en gran parte basado en la distribución de materiales para trabajar en el aula que eran entregados a estudiantes y docentes: los "cuadernos de trabajo" y "cuadernos del docente" respectivamente. Estos materiales se fundamentaron en que "los alumnos tienen una concurrencia irregular a la escuela (...) que exige modalidades de aprendizaje autónomo" y, aunque bajo la aclaración de que no pretendían sustituir la presencia de los docentes, apelaban fuertemente a "la autonomía en el aprendizaje que supone tomar decisiones respecto de tareas cotidianas". ${ }^{33}$

Es posible advertir la vinculación de proyectos desarrollados durante estos años con los talleres y las actividades de desarrollo comunitario del EMER y del Proyecto IER. Particularmente en torno a la incorporación del tercer ciclo EGB se destacó el desarrollo de los llamados Proyectos de Calidad de Vida, que estaban vinculados a los Contenidos Básicos Comunes, no eran contemplados dentro de la carga del horario escolar y se sostenían a través del trabajo de docentes tutores y profesores itinerantes, quienes también recibían cuadernillos que acompañaban la tarea. Entre estas propuestas se encontraban proyectos de huerta escolar, vivero forestal, conservación de frutas y hortalizas y se señalaba la finalidad de incorporar "los conocimientos y prácticas que cada comunidad ha construido a lo largo de su historia y se generará, también, la posibilidad de transferir a la comunidad los saberes adquiridos en el trabajo escolar". ${ }^{34}$

Según hemos visto en una investigación realizada en el Departamento La Paz, desde fines de la década de 1990, cuando dejó de funcionar el EMER, la recuperación de tareas que involucraban el trabajo de huerta en la escuela primaria se relaciona con la creación de

\footnotetext{
${ }^{31}$ Provincia de Entre Ríos. Informe elevado por la provincia a la Nación, 1998.

32 Provincia de Entre Ríos. CGE Res. 151/99

${ }^{33}$ Argentina. Ministerio de Cultura y Educación. Plan Social Educativo. Proyecto Fortalecimiento de la

Educación Rural. La propuesta de enseñanza y los primeros 15 días, página 10.

${ }^{34}$ Argentina. Ministerio de Cultura y Educación, 1999, página 33.
} 
diferentes proyectos extracurriculares. En este sentido, en 1999, siguiendo las propuestas y recomendaciones de los cuadernillos recibidos para los Proyectos de Calidad de Vida, se optó por realizar una huerta escolar y comunitaria y el EMER fue evocado como antecedente a la hora de elaborar el proyecto y proponer la articulación entre instituciones que el proceso de nuclearización había originado. Aunque la propuesta debía estar destinada al EGB 3, aquí se realizó incluyendo también a la población escolar de todos los ciclos de las escuelas de la zona. Además, tal como establece el diseño del proyecto, fue coordinado por un profesor itinerante, en este caso de Tecnología, que anteriormente se había desempeñado como tallerista del EMER y cuyo cargo fue reconvertido. ${ }^{35}$ Para desarrollar las actividades que congregaron cuatro instituciones, se eligió la ex escuela-núcleo por su infraestructura y utilizaron las cartillas producidas por el Programa Pro Huerta del INTA (Schmuck, 2020). Cabe señalar que en este sentido una de las responsables del EMER participó en la organización del Prohuerta en Entre Ríos.

Asimismo, por esos años emerge la importancia del Programa de Reforma e Inversión en el Sistema Educativo (PRISE), que estaba financiado por el BID y también impulsó el desarrollo de proyectos que buscaban la participación de la comunidad, así como inversiones en materiales, equipamiento e infraestructura. ${ }^{36}$ En este sentido, estas inversiones, aunque no estuvieran realizadas en el marco del Proyecto 7, en las instituciones aparecen relacionadas con el programa:

En el 97 y 98 recibimos muchas veces visitas de "gente de Paraná", decíamos. “¿Qué nos estarán mirando?”, decíamos. Pero el Proyecto 7 cuando viene, no viene solo. Cuando lo instalan, vienen varias cosas. En el 98' se creó la sala de primeros auxilios dentro del predio de la escuela para que educación y salud esté cubierto mínimamente. (Entrevista a ex docente y directora de educación primaria rural y ex directora de Educación Rural del CGE, 24/04/2020).

Fue recién en 1999 que se procedió a la creación del EGB 3 en todo el territorio entrerriano, estableciendo la obligatoriedad de los diseños curriculares elaborados en la provincia. ${ }^{37}$ Según datos de abril de ese año, el EGB 3 funcionaba en 224 escuelas rurales con 19 sedes, alcanzando una matrícula de 2107 estudiantes (Jacinto y Golzman, 2006). No obstante, con el inicio de la segunda gestión de Montiel (1999-2003), enseguida se generaron nuevas modificaciones: en el 2000 se creó la Escuela Intermedia y en 2001 sancionó la Ley Provincial de Educación. ${ }^{38}$ De acuerdo con la nueva legislación, la Escuela Intermedia fue

\footnotetext{
${ }^{35}$ Este caso da cuenta de una tendencia más amplia en la cual la mayor parte de los cargos de los profesores de los talleres del EMER fueron reconvertidos a cargos docentes (Petitti, 2020). En el mismo sentido, un trabajador del PROMER y CGE expresa que "existen cargos que eran de instructores de los talleres en las escuelas núcleo, que al dejar de funcionar quedaron trabajando (...). Al ser titulares no se los pudo reestructurar dados los derechos adquiridos". (Entrevista a ex docente y director de educación primaria rural y técnico de PROMER y CGE, 22/04/2020).

${ }^{36}$ El objetivo del Programa se contextualizaba en el "cumplimiento de los objetivos de la reforma de la Educación Media (EM), cuya implantación aún está incompleta en la mayoría de las provincias y en el apoyo focalizado a la población escolar que se encuentra en situación de mayor riesgo social y educativo". BID-Argentina. 1999

37 Provincia de Entre Ríos, CGE Resolución 2860/98.

${ }^{38}$ A nivel nacional, durante la presidencia de Fernando de la Rúa (1999-2001), candidato de la Alianza para el Trabajo, la Justicia y la Educación, el PSE fue reemplazado por el Programa Escuelas Prioritarias. Este programa, que tuvo una vigencia de pocos meses y luego fue sucedido por el Programa de Acciones Compensatorias en Educación (PACE), estaba orientado específicamente a los sectores más vulnerables de la población de zonas rurales y urbanas, a personas con necesidades educativas especiales y a adultos que no terminaron su escolaridad básica (Ministerio de Educación, 2000). Más allá de los cambios de nombres entre los programas, continuaron enmarcadas en políticas compensatorias y focalizadas dirigidas a poblaciones en desventaja social y pedagógica, a las escuelas cuya población pertenece a los sectores en mayor riesgo socioeducativo (Bordegaray y Novaro, 2004).
} 
concebida como una unidad educativa independiente y con sus propios directivos que, hasta que se generaran los espacios adecuados para su funcionamiento, podía localizarse en escuelas EGB 1 y 2, Escuelas Polimodales o Escuelas Núcleo de Agrupamiento. En las zonas rurales esto significó fundamentalmente la organización de agrupamientos que establecieran una escuela sede, la Escuela Intermedia, que recibiera a los egresados de las escuelas EGB 1 y 2 de la zona. ${ }^{39}$ En los departamentos del norte nuevamente se tomó como base la organización previa de los conjuntos nuclearizados del EMER y en algunos de ellos para trasladar a los alumnos se planteó desde la comunidad educativa la posibilidad de utilizar las mismas camionetas que serían conducidas por los choferes que continuaban en los establecimientos realizando tareas de mantenimiento. En términos generales, además, las escuelas que habían sido núcleo del EMER y entonces contaban con mejores instalaciones fueron elegidas para la conformación del Polimodal y/o cuando más adelante se crearon las escuelas secundarias, aunque nuevamente no se trata de una regla general, ya que la implementación estuvo marcada por procesos de apropiación y disputa en los espacios rurales.

Estos cambios, que además fueron realizados en un contexto de crisis económica, social e institucional en el país y la provincia, con extensos y resonantes paros de docentes, generaron resistencias en su implementación, aunque el antecedente del Proyecto 7 en las instituciones significó que muchos mecanismos y estrategias desarrolladas en las escuelas -entre ellas, el uso de cuadernillos y la continuidad de los Proyectos de Calidad de Vidase presentaran más como una continuidad que como una interrupción. De este modo, en instituciones y entre docentes y directivos que vivenciaron estas transformaciones, muchas veces Proyecto 7, EGB 3 Rural y Escuela Intermedia aparecen como sinónimos o se sitúan en relación con diversas periodizaciones que no siempre coinciden con las normativas y las fechas de implementación de los programas.

\section{El Proyecto de Mejoramiento de la Educación Rural para todas las escuelas rurales}

Luego de la sanción de la Ley de Educación Nacional en 2006, que se propuso avanzar hacia la unificación y homogeneización de la estructura académica en todo el territorio nacional y extendió la obligatoriedad a toda la secundaria, Entre Ríos sancionó en 2008 una nueva Ley de Educación que modificó los niveles del sistema educativo y estableció como una de las ocho modalidades del sistema educativo la Educación Rural complementada con la de Islas. Aunque a partir de entonces la provincia ha incorporado esta modalidad al presupuesto regular y la administración escolar (Mayer y Vlasic, 2016), podemos afirmar que gran parte de las acciones destinadas a la educación rural en los últimos años se han encontrado ligadas a la implementación del primer Proyecto de Mejoramiento de la Educación Rural (PROMER) I y su continuidad a partir del PROMER II. Parte del financiamiento del programa estuvo destinado a la ampliación del Proyecto Horizontes, que tuvo una implementación parcial en la provincia de Entre Ríos. Surgió en 2008, durante la presidencia de Cristina Fernández (2007-2015) con el objetivo de que "los jóvenes rurales puedan cursar el Ciclo Básico de la Educación Secundaria obligatoria en escuelas cercanas a sus lugares de residencia, con formatos organizacionales adecuados a cada situación local y con la posibilidad de ampliar sus marcos de referencia a partir de actividades compartidas con otros docentes y jóvenes de zonas cercanas". ${ }^{40}$

\footnotetext{
${ }^{39}$ Provincia de Entre Ríos. CGE Res. 0397/00.

${ }^{40}$ Argentina. Ministerio de Educación, Cuaderno para el docente. Presentación del Proyecto Horizontes, 2009. Se trató de una propuesta pedagógica y didáctica que implicó la producción y utilización de materiales de desarrollo curricular impresos para alumnos y docentes, la incorporación de recursos multimediales, especialmente programas de TV, la provisión a las escuelas de los recursos necesarios (TV, DVD, computadora, impresora) y la continuidad de financiamiento de Proyectos Productivos de Base Local iniciados con la propuesta del Programa Social Educativo.
} 
El PROMER I se basó en un préstamo para el financiamiento de políticas destinadas a todos los niveles de la educación rural con fondos provenientes del Banco Mundial, específicamente del Banco Internacional de Reconstrucción y Fomento (BIRF) por un monto de 150 millones de dólares. Se implementó entre 2007 y 2010 y luego con una prórroga hasta 2013, con el objetivo de "respaldar la política del gobierno nacional para mejorar la cobertura, la eficiencia, y la calidad del sistema educativo nacional y mejorar la gestión del Sistema Educativo a través del fortalecimiento de la capacidad normativa, de planeamiento, información, monitoreo y evaluación en los niveles nacionales y provinciales". ${ }^{41}$ A diferencia de los proyectos anteriores, que se centraron en algunas zonas y/o en relación con políticas focalizadas eligieron premeditadamente una población destinataria, el PROMER I se propuso abarcar todo el universo de escuelas rurales, aunque para acciones determinadas se buscó establecer prioridades para asegurar la atención a las escuelas más aisladas. ${ }^{42}$

El programa organizó su implementación a nivel local en relación con el establecimiento de agrupamientos de escuelas, integrados "por un conjunto de hasta 15 escuelas que se encuentran próximas geográficamente y, siempre que las condiciones de existencia y distancia lo permitan, que converjan con la zona de supervisión de Nivel Primario, con una escuela media de referencia". ${ }^{43}$ Como podemos advertir a partir de las continuidades con los programas que hemos desarrollado anteriormente, esta perspectiva de trabajo significa recuperar "experiencias nacionales y provinciales que brindan respuestas situadas a las problemáticas comunes de varias escuelas en el marco de redes, núcleos, unidades de gestión locales y otras diversas formas de trabajo compartido entre instituciones". ${ }^{44}$ En palabras de la ex directora de educación rural de Entre Ríos,

No es un puñado de escuelas que se juntan porque sí, sino para interactuar, enriquecerse, estudiar (...). Si vos tenés un nucleamiento o agrupamiento, tiene que tener primarias y secundarias, lo que se debería trabajar sería la trayectoria, para que podamos pensar en trayectorias que discurran por canales adecuados, en estrategias que contribuyan a lo que va a dar continuidad a la secundaria. En la época del EMER ya se hacía así, era diferente pero nos reuníamos, hacíamos equipo entre escuelas de un núcleo (...). Antes era nucleamiento porque tenían núcleo, hoy le llamamos

\footnotetext{
${ }^{41}$ Ministerio de Educación de la Nación. Proyecto de Mejoramiento de la Educación Rural- Convenio de préstamo BIRF Nro.7353-AR. Manual operativo, 2007.

42 De hecho, en el marco del PROMER I se financió el Primer Relevamiento de Escuelas Rurales (RER), realizado entre 2006 y 2009 con el objetivo de obtener información sobre todas las escuelas rurales del país. El RER recolectó información de un total de 15.596 escuelas rurales ubicadas en poblaciones de menos de 2000 habitantes o en campo abierto y permitió generar distintos indicadores georreferenciados relevantes para la planificación y evaluación de la política educativa.

${ }^{43}$ Ministerio de Educación de la Nación. Proyecto de Mejoramiento de la Educación Rural- Convenio de préstamo BIRF Nro.7353-AR. Manual operativo, 2007.

${ }^{44}$ Consejo Federal de Educación. Resolución Nº128/10, página 9. Esta resolución, que refiere a las políticas para la modalidad rural integrando al PROMER, avala distintos modelos de organización escolar adecuados a cada contexto "en vistas a proveer de justicia curricular a todas las ofertas" y detalla la política de instauración de agrupamientos. En consonancia con la normativa nacional y las últimas directrices provinciales en la materia (resolución del CGE 850/2007) recogidas en la resolución 125/2015, en Entre Ríos se pueden identificar distintos modelos organizativos y pedagógicos: ciclos básicos localizados en escuelas primarias; ciclos básicos localizados en escuelas primarias con extensión progresiva hasta el ciclo orientado; escuelas multinivel, que incluyen los niveles inicial, primario y secundario; escuelas secundarias completas; escuelas secundarias con residencia albergue; instituciones organizadas en torno a pluriaños en el ciclo básico y multiaños en el ciclo orientado. CGE. Serie estadística escuelas de nivel inicial, primario y secundario en contexto rural. 2018. Dirección de Educación Secundaria.
} 
agrupamiento. (Entrevista a ex docente y directora de educación primaria rural y ex directora de Educación Rural del CGE, 24/04/2020).

Entre las acciones efectuadas en el marco del programa en todo el país, nuevamente se destaca la inversión realizada en equipamiento e infraestructura: bibliotecas, ludotecas, dispositivos tecnológicos y multimediales, laboratorios escolares, materiales impresos para alumnos y docentes de todos los niveles, así como la realización de obras que atendieron falencias en la prestación de servicios básicos en las escuelas, como agua potable y energía eléctrica, nuevas aulas y edificios (González et al, 2015). En Entre Ríos, no obstante, se subraya la importancia de los encuentros de Fortalecimiento de la Enseñanza en las Escuelas Primarias Rurales que se desarrollaron en entre 2008 y 2010, en cuatro sedes (Concordia, Islas del Ibicuy, Nogoyá y La Paz), con encuentros presenciales cada 15 días y trabajo en las instituciones y los agrupamientos. En cambio, durante el período no se avanzó en obras de infraestructura.

En 2015, ya bajo la órbita del gobierno nacional del candidato de la Alianza Cambiemos Mauricio Macri (2015-2019), comenzó a implementarse el PROMER II por un monto de 250 millones de dólares. Aprobado con el objetivo de reducir las tasas de repitencia en aulas de zonas rurales y aumentar la inscripción y las tasas de terminación de los estudios en la educación secundaria en las zonas rurales, el proyecto ha otorgado centralidad al nivel secundario, lo que se traduce en que el $80 \%$ del monto total se destine al nivel. Las inversiones consideradas incluyen el mejoramiento de las condiciones de funcionamiento de las escuelas rurales -desde obras de infraestructura hasta mantenimiento y adquisición de equipamiento-, el fortalecimiento del vínculo entre las escuelas y las familias y la mejora de la enseñanza y la gestión escolar -con acciones de capacitación, producción y distribución de materiales de enseñanza, entre otros. ${ }^{45}$ A pesar de que en 2019 culminaba su plazo formal, la finalización del PROMER II se extendió hasta fines de $2020 .^{46}$

Entre las inversiones sobresalientes realizadas con recursos del PROMER II durante 2017 y 2018 en Entre Ríos, se encuentra la entrega de equipamiento escolar a las escuelas rurales de nivel secundario, la distribución de mobiliario escolar en más de 500 escuelas rurales de nivel inicial y primario, ${ }^{47}$ la construcción de una escuela en el departamento Feliciano, el inicio de obras de construcción de una secundaria y refacciones en otra institución en el departamento Concordia. ${ }^{48}$ En lo que refiere específicamente al nivel secundario, se destacan los Proyectos Productivos de Base Local (PBL) destinados al Ciclo Básico de la Secundaria, que implican "transferencias de fondos a escuelas para la implementación de proyectos pedagógicos vinculados al desarrollo local", se proponen involucrar a los actores locales y que "los jóvenes cuenten con herramientas para participar en la comunidad como promotores locales del desarrollo". ${ }^{49}$ En los materiales del programa, se apela a la búsqueda de relaciones de cooperación entre las instituciones y otros actores como el municipio, las familias de los

45 Argentina-BIRF, 2015. La negociación para la continuidad del proyecto comenzó a realizarse durante la gestión de Cristina Fernández y continuó durante el gobierno de Macri.

${ }^{46}$ Los informes de auditoría refieren a que los fondos disponibles fueron sub-ejecutados, por lo que futuros trabajos que avancen en el estudio del programa en los años recientes podrán realizar nuevos aportes. Auditoría General de la Nación. Informe de auditoría independiente sobre los estados financieros del "Segundo Proyecto de Mejora para la Educación Rural-PROMER. Gerencia de la Deuda Pública- Departamento de Control del Endeudamiento con Organismos Financieros Internacionales, 2018.

${ }^{47} \mathrm{http} / / /$ cge.entrerios.gov.ar/educacion/informes-de-gestion/

${ }^{48}$ Provincia de Entre Ríos. Unidad Ejecutora Provincial-Boletín oficial. Resoluciones aprobadas, 2017.

49 Argentina. Ministerio de Educación de la Nación. Los proyectos escolares productivos de base local como estrategia de enseñanza. Documento de trabajo interno, sin publicar. Disponible en CGE- Dirección de Educación Secundaria. 2017, página 3. 
alumnos, los ex alumnos, las organizaciones gubernamentales y no gubernamentales locales y de otros ámbitos (regionales, provinciales, etc.). ${ }^{50}$

En Entre Ríos, al igual que hemos mencionado para el EMER, las gestiones del PROMER II se realizan a través de la Unidad Ejecutora Provincial (UEP), que a su vez tiene a cargo la implementación de otros proyectos con financiamiento nacional e internacional. Además de estar a cargo del pago de contratos y rendiciones en el marco de las diferentes líneas del proyecto, la UEP, aunque en articulación con el CGE, adquiere protagonismo en relación con el desarrollo de obras de infraestructura y adquisición de mobiliario escolar:

En PROMER I el ente ejecutor estaba centralizado en el CGE, que no es un ente ejecutor nato, no tiene la estructura y la conformación de ente ejecutor, con lo cual fue muy difícil la licitación de las obras, la adjudicación, la contratación. No dieron resultado en la parte infraestructura como ahora (...). El CGE tiene una dirección de planeamiento y planificación, ellos tienen todas las bases estadísticas y conocen las necesidades (...) con lo cual ellos definen en qué lugar se implementarían las obras y el programa de necesidades. (Entrevista a coordinador ejecutivo adjunto de la UEP, 08/07/2020).

A partir de 2016, la interlocución entre el CGE y la UEP estuvo a cargo de la Dirección de Educación Rural e Islas creada como parte de la estructura del organismo con el objetivo de atender las particularidades de las instituciones en esos contextos ${ }^{51}$. Sin embargo, en noviembre de 2017 se resolvió el cierre de la Dirección, fundamentado en cuestiones presupuestarias, y la absorción de las funciones por parte de las direcciones de Educación Primaria, Inicial y Secundaria. Diferentes trabajadores del CGE y PROMER señalan que particularmente los niveles inicial y secundario se vieron "perjudicados" por esta medida:

Estuvo poco tiempo funcionando, pero la comunicación que se pudo establecer con las escuelas y que se comenzaba a establecer fue destacada. (...) Esto afectó más que nada al nivel inicial y secundario (...). Dentro de la dirección de primaria funcionó durante mucho tiempo una Subdirección de Rural y luego de cerrada la Dirección de Rural, la dirección de Primaria como siempre lo hizo siguió con este accionar específico para las escuelas rurales. (Entrevista a ex docente y director de educación primaria rural y técnico de PROMER y CGE, 22/04/2020).

La encargada de la línea de los Proyectos Productivos de Base Local del PROMER II, que fueron puestos en marcha en la provincia a partir de gestiones realizadas desde la Dirección de Educación Rural, ${ }^{52}$ señala:

Para poder ejecutar estos Proyectos PBL, PROMER contrata perfiles que trabajan en relación con el CGE pero de alguna manera tenemos

\footnotetext{
${ }^{50}$ Argentina. Ministerio de Educación de la Nación. Los proyectos escolares productivos de base local como estrategia de enseñanza. Documento de trabajo interno, sin publicar. Disponible en CGE- Dirección de Educación Secundaria. 2017, página 4.

${ }^{51}$ Provincia de Entre Ríos. CGE Res. 026/16.

${ }^{52}$ Estos proyectos tienen como antecedentes los Proyectos Institucionales de Base Local financiados por el PROMER I, que en la provincia no habían sido implementados. Según expresa la ex directora de Educación Rural, simplemente porque "nadie los había bajado" a la provincia". (Entrevista a ex docente y directora de educación primaria rural y ex directora de Educación Rural del CGE, 24/04/2020).
} 
cierta autonomía ${ }^{53}(\ldots)$ en sí mi función es recorrer todas las escuelas y los departamentos, por eso es territorial (...) Se sintió mucho la disolución de la Dirección, de una persona encargada específicamente de ejecutar líneas rurales. Porque a las escuelas secundarias les llega mobiliario cuando PROMER manda pero solo está esta línea de acción [PBL]. Porque en la dirección general de nivel [de Educación Secundaria del CGE] es como que la ruralidad está al margen, como somos menos parece que no hay tantas necesidades, tantos problemas. (Entrevista a referente de PBL-PROMER, 22/04/2020).

Desde su implementación en 2016, se registra un significativo incremento de las escuelas involucradas en los PBL: en 2017 se realizó en 37 escuelas y al año siguiente llegó a los 17 departamentos e involucró a 87 instituciones, entre las que se encontraban 81 escuelas rurales, dos escuelas que funcionaban como anexos de secundaria y cuatro escuelas con multiaño. Las propuestas realizadas se caracterizaron por abordar diversas actividades, entre las que se destacaron las de huerta y vivero $(23 \%)$ y dulces y conservas $(11,5 \%)$, seguidas por experiencias de panificación (9\%), producción de plantas (9\%) y periódico escolar $(7 \%){ }^{54}$

A propósito de la diversidad de proyectos existentes, nuevamente interesa referir a la investigación realizada en el Departamento La Paz: en una escuela secundaria se eligió hacer un emprendimiento panaderil evaluando la inexistencia de esa producción en la zona. Esta demanda "local" se articuló como el principal argumento a la hora de situar el emprendimiento como una estrategia de desarrollo local y entre las actividades realizadas se elaboró pan y algunas tortas, investigaron las propiedades de los alimentos y diseñaron los procesos de producción, aunque fundamentalmente se trabajó con los estudiantes en torno a la capacidad de armar un negocio propio o emprendimiento, atendiendo a las estrategias de comunicación y marketing para la venta de productos. De este modo, en cada etapa del proceso se identificó como el principal objetivo, explicitado en un informe que elabora de la directora, "preparar a nuestros estudiantes en un oficio que pueda dar respuestas inmediatas". ${ }^{55}$ En este punto, es posible advertir una clara diferencia con proyectos previos realizados en la escuela y las fundamentaciones de las asignaturas que entre 2005 y 2011 integraron la modalidad de Bienes y Servicios del Polimodal en la escuela, que luego fue reemplazada por la terminalidad en Economía y Administración para el Ciclo Orientado. En estos casos, se remitía al "desarrollo sustentable" y el "desarrollo de la comunidad", en estrecha relación con la inclusión de saberes ligados a la producción agropecuaria de la zona. Según una referente de PBL:

En el PBL claramente dice que se apuesta a la formación laboral, que es lo que a las escuelas rurales les interesa, que se preocupan mucho porque los chicos aprendan algo, un oficio (...). Pero luego se empezó a poner más énfasis en que lo importante eran los saberes curriculares (...). Desde la dirección [de Educación Secundaria del CGE] decían que para eso están las escuelas técnicas, que enseñan oficios, nosotros no enseñamos oficio. (Entrevista a referente de PBL-PROMER, 22/04/2020).

\footnotetext{
${ }^{53}$ No obstante, en otros casos, las personas contratadas para desempeñarse en PROMER también desempeñan otras funciones en el CGE.

${ }^{54}$ CGE. PROMER II. Proyectos Productivos de Base Local - PBL. Dirección de Educación Secundaria, 2018.

${ }^{55}$ La Paz. Archivo E. Secundaria-Informe PROMER, 2018
} 
Estas diferentes concepciones en juego parecen haber atravesado la implementación de los PBL en toda la provincia.

\section{Conclusiones}

Los programas orientados a la educación rural que se implementaron en Entre Ríos, y particularmente en el norte en los últimos cuarenta años, representan una combinación de prácticas superpuestas. Sus objetivos fundamentales y su organización han sido construidos de manera articulada. En una breve recapitulación a lo largo de cuatro décadas podrían distinguirse en Entre Ríos cuatro programas nacionales y uno provincial que, en mayor o menor medida según los casos, han estado superpuestos tanto en lo que atañe a los momentos históricos de su implementación, como a los actores que participaron en los mismos: EMER, EMETA, IER, Proyecto 7 y PROMER.

Si bien el Proyecto IER no se implementó en el norte de la provincia -ya que su objetivo era ampliar la nuclearización a otros departamentos de la provincia-, el norte zona de atracción de otros programas de desarrollo rural-, se constituyó en espacio privilegiado de los programas educativos para la educación rural en la provincia. De esta forma nos permitió estudiar de qué manera la constitución articulada de objetivos fundamentales y la organización de los diferentes programas se vincula con la continuidad de muchos de sus actores. Tanto los funcionarios como los docentes, directivos, familias y choferes encargados de la nuclearización, participaron de las diferentes experiencias.

Respecto a sus objetivos fundamentales nos referimos al proyecto de desarrollo rural con el que se relacionan o interpelan los programas. Desde los primeros programas se remite a la necesidad de frenar el proceso de migración a las ciudades, a la necesidad de incentivar el arraigo, a la educación técnica ligada al entorno y a la relación con la comunidad y con lo local. Como telón de fondo, persiste la centralidad de las instituciones de educación rural: escuelas como un espacio habitado, disputado socialmente.

Desde la necesidad de erradicar las "escuelas rancho" en adelante, vimos que las inversiones en edificación y equipamiento aparecen como un componente fundamental en las políticas destinadas a la educación rural, que a medida que pasan las décadas sigue apareciendo como un espacio con carencias en infraestructura. En relación con los proyectos educativos, que en algunos casos aparecen como las "líneas pedagógicas de los programas", advertimos la preocupación del EMER por la relación entre la educación formal y las competencias laborales o la orientación utilitaria de la escuela. Al mismo tiempo, si acaso el EMETA continúa con esta tradición y da cuenta de una multiplicidad de relaciones posibles entre las escuelas agrotécnicas, las comunidades y el resto de las instituciones educativas, en las décadas siguientes vemos que esa relación se debilita y el "trípode educación-trabajo-producción" se sitúa en relación específica con la orientación técnico-profesional. En la misma línea, la preocupación por la radicación en el medio y el arraigo en el espacio rural, si acaso sigue presente en algunas fundamentaciones, desde el Proyecto de Integración en adelante se reemplaza por la importancia de la participación de la "comunidad"; el interés por "lo local" aparece despojado de la actividad económica de la zona para "recuperar" experiencias, habilidades y saberes que dialogaban con los intereses por superar el aislamiento o aprovechar recursos en un contexto de políticas de descentralización, al mismo tiempo que va creciendo la importancia dada a la inclusión educativa y otros indicadores, fuertemente valorados en las evaluaciones del PROMER, ligados a la promoción, la superación de la sobreedad y el egreso.

Respecto a la organización, la nuclearización ha sido una estrategia que persiste en el diseño de las políticas pero también se recupera y valora desde el territorio: en las instituciones del norte de la provincia en las que centramos nuestro trabajo de campo, la creación del EGB 3 o escuelas intermedias recupera esquemas de aglomeración de escuelas que caracterizó a los 
programas EMER y EMETA, incluyendo la recuperación y capitalización - muchas veces a partir de la experiencia de la propia comunidad educativa y sus trabajadores en el territorio de relaciones previas y recursos (como el vehículo).

En suma, identificando más permanencias que quiebres, hemos podido señalar un hilo conductor que enlaza los objetivos de las políticas de desarrollo que recuperamos a lo largo de cuatro décadas. Las articulaciones a veces se plasman en los documentos que podemos encontrar en las escuelas o son explícitamente evocadas por docentes, directivos y familias; otras veces, pueden rastrearse a partir de las huellas entre los diferentes proyectos puestos en práctica o incluso a partir de la imposibilidad de diferenciar entre los diferentes programas y sus periodizaciones en las instituciones y los trabajadores que los protagonizaron.

\section{Bibliografía}

Aguilar, L. (1992). "Estudio introductorio". En: Aguilar (Ed.) Problemas públicos y agenda de gobierno (pp. 15-72). México: Miguel Ángel Porrua.

Bordegaray, D. y Novaro, G. (2004). "Diversidad y desigualdad en las políticas de Estado. Reflexiones a propósito del proyecto de Educación Intercultural Bilingüe en el Ministerio de Educación”. Cuadernos de Antropología Social, 19, 101-119.

Bouzas, R. y Knaack, P. (2009). El BID y medio siglo de Integración Regional en América Latina y El Caribe. Revista Electrónica Instituto para la Integración de América LatinaBID, 29 (13), 15-28.

Brasky O. y Pucciarelli A. (1997). El agro pampeano: el fin de un período. Buenos Aires: FLACSO-UBA.

Brumat, M.R (2011). Maestros rurales: condiciones de trabajo, formación docente y práctica cotidiana. Revista Iberoamericana de Educación, 55(4), 1-10. DOI: https://doi.org/10.35362/rie5541580.

Catullo, M. (2006). Ciudades relocalizadas. Una mirada desde la antropología social. Buenos Aires: Biblos.

Celman, S., Rafaghelli, M, Galarraga, G. y Martínez, M. (2000). Evaluación del Tercer Ciclo EGB - Escuelas Rurales Proyecto 7. Revista Presencia-Asociación Gremial del Magisterio de Entre Ríos, 72, 20-21.

Cragnolino, E. (2000). La modernización de la escuela Agrotécnica. Cuadernos de Educación, 1 (1), 179-190.

Engler, P, Rodríguez, M, Cancio, R, Handloser, M. y Vera, L. M. (2008). Zonas Agro Económicas homogéneas. Entre Ríos Descripción ambiental, socioeconómica y productiva. Informe del Instituto Nacional de Tecnología Agropecuaria (6). Entre Ríos: INTA.

Estrada Álvarez, J. (2009). El BID en América Latina: 50 años reproduciendo la desigualdad: campo de acción institucional, derecho, transformaciones sociales y globalización. Bogotá: Instituto Latinoamericano de Servicios Legales Alternativos. 
Frankowski, T., Romero y Osorio (2019). Educación popular y Rural. Análisis y reflexiones de la experiencia del EMETA en Córdoba. En: III Jornadas académicas HEAR, Universidad Nacional de San Luis, San Luis.

González, D., Mamanis, S., Prudant, E. y Scarfó, G. (2015). Panorama de la Educación Rural en Argentina. Temas de Educación. Boletín $N^{\circ} 12$. Ministerio de Educación de la Nación. Recuperado de http://portales.educacion.gov.ar/wp-content/blogs.dir/37/files/2015/12/Boletin-12-1_12_15.pdf.

Gutiérrez, V.T. (2012). Políticas educativas y enseñanza agraria, una relación compleja. Buenos Aires (Argentina), 1960-2010. Revista Iberoamericana de Educación, 58 (3), 1-14. DOI: https://doi.org/10.35362/rie5831435.

Gutiérrez, V.T; Jorge Navarro, M. y De Marco, C. (2014). Historia, cultura y memoria en el mundo rural. Educación agraria del Centenario al Bicentenario, 1910-2010. Cuadernillo de difusión. Recuperado de https://www.aacademica.org/rosa.maria.celeste.de.marco/12.pdf.

Jacinto, C. y Caillods, F. (2006). Tensiones, lecciones e interrogantes en los programas de equidad en educación básica. En: Caillods, F. \& Jacinto, C. (Coords.), Mejorar la equidad en la educación básica. Lecciones de programas recientes en América Latina (pp. 21-55). Paris: IIEP-UNESCO.

Jacinto C. y Golzman, G. (2006). El Programa Tercer Ciclo en Escuelas Rurales. Una estrategia para extender la escolaridad en la educación básica argentina. En F. Caillods, F. y C. Jacinto (Coords.), Mejorar la equidad en la educación básica. Lecciones de programas recientes en América Latina, (pp. 199-258). Paris: IIEP-UNESCO.

Jorge Navarro, M. (2015). La implementación del programa de expansión y mejoramiento de la educación rural (EMER) en la provincia de Salta 1980-1989. En: XV Jornadas Interescuelas/Departamentos de Historia, Comodoro Rivadavia, Chubut.

Leguizamón, L. (2013). Programa E.M.E.T.A. Política nacional aplicada con perspectiva local. El caso de la Escuela Agrotécnica de Machigasta (Departamento Arauco-La Rioja). En: XIV Jornadas Interescuelas/Departamentos de Historia. Departamento de Historia de la Facultad de Filosofía y Letras. Universidad Nacional de Cuyo, Mendoza.

Leguizamón, L. y Jorge Navarro, M. (2013). Programa EMETA en Salta y La Rioja: diagnósticos e implementación 1987- 1993. En: L. Blacha y Poggi, M. (coords.), Redes y representaciones del poder rural (pp. 155-174). Rosario: La quinta pata \& camino ediciones.

Mayer, S. y Vlasic, V. (2016). Escuelas Secundarias Rurales: Estudio descriptivo de la modalidad rural de educación secundaria en Entre Ríos. Informe Final. Proyecto PIDA. Entre Ríos: Universidad Autónoma de Entre Ríos.

Novomisky, N. e Iñiguez S. Comp. (2015). El PROMER: políticas educativas e inclusión social: una mirada reflexiva acerca de la ruralidad en la provincia de Buenos Aires. La Plata: Ediciones EPC.

Olmos, A. y Palladino, L. (2019). Gestionar la mejora de la educación rural en un país federal. Planificación, financiamiento y administración de un programa socioeducativo en la República Argentina. Estudios rurales, 9 (17), 1-18. 
Petitti, M. (2020a). "Procesos de apropiación local del Programa de Expansión y Mejoramiento de la Educación Rural en los años '80 (Entre Ríos, Argentina)." History of Education in Latin America, HistELA, 3, (1),1-18.

Petitti, M. (2020b). "Estado, políticas públicas y funcionarios en un contexto de transformaciones políticas: El EMER en la provincia de Entre Ríos (1978-1992)." Población y Sociedad, 27 (1), 89-113.

Plencovich, M. (2013). La deriva de la educación agropecuaria en el sistema Educativo argentino. Tesis de doctorado. Universidad Nacional de Tres de Febrero, Caseros, Buenos Aires.

Prudant, E. y Scarfó, G. (2018). La extensión de la educación secundaria en el ámbito rural estrategias para su logro en dos jurisdicciones. Serie Apuntes de Investigación $\mathrm{N}^{\circ} 15$. Buenos Aires: Ministerio de Educación, Cultura, Ciencia y Tecnología. Dirección de Información y Estadística Educativa (DIEE).

Schmuck, E. (2020). 'Somos jóvenes y estudiantes del campo'. Una etnografía sobre experiencias formativas y educación secundaria en el norte entrerriano. Tesis de doctorado. Universidad Nacional de Entre Ríos, Parana, Entre Ríos.

Yentel, N. (2011). Cambio en educación. Acerca de los aspectos que concurren a la configuración de una trama de interrupción: Un estudio de caso. Tesis de Maestría. Universidad de Buenos Aires, Buenos Aires. 